\title{
Correspondence
}

\section{Patients' participation in MB Finals in Psychiatry}

\section{DeAR SIRS}

I am writing in response to the interesting article by Drs Persaud \& Meux (Psychiatric Bulletin, February $1990,14,65-72)$. As I have been involved with organising MB Finals in Psychiatry on three occasions, I thought it may be of relevance to report on the effect of the examination on the mental states of the 80 patients good enough to participate. Each patient was assessed by the two examiners, as well as the nursing and medical staff involved in their care as suitable cases for Finals.

The commonest reaction was anxiety or plain boredom. However, six patients showed significant changes in their mental states during the process. One patient with a schizoaffective illness who had been stable for several weeks, suddenly became grandiose and euphoric in the middle of his first morning in Finals. When not being interviewed, he acquired a large shopping trolley, chef's hat and uniform and propelled himself up and down the corridor of the examination hall. This behaviour had a beneficial effect on the other patients, examiners and candidates, with requests made that he became a regular attender to brighten up the proceedings. Unfortunately he later became suddenly sexually disinhibited when he saw the female medical student he was to be interviewed by. He had to be interviewed, however, as there was no time to arrange an alternative patient. To remedy any potential hazard a large, strong female nurse was used as a chaperone, which must be an uncommon experience in Final MB in psychiatry! Needless to day the candidate passed with flying colours.

Another patient was on the way to the room where Finals were to be held and without warning became suspicious that it was a police station and doublebacked and ran, absconding into freedom! One chronic schizophrenic patient became manneristic and irritable and refused to be interviewed unless he had his requisite supply of cigarettes, which had run out! Another chronic schizophrenic who was at that time symptom-free (and in fact had never experienced auditory hallucinations in his illness), became very suspicious and asked me if he should be hearing voices if he had this diagnosis, as everybody was asking him about this! A rapid-cycling manic-depressive who had had his longest period of mood stability prior to Finals, became irritable (mostly with examiners who were asking "stupid questions" of the candidate) following an incident in which the lock of the toilet had jammed; and there was a delay before this could be opened. One previously-recovering depressed patient developed a panic attack when inadvertently left alone in the examination room for five minutes after her interviewer and the examiners had left ahead of schedule.

I think that this level of morbidity and relapse $(6 / 80$ or $13 \%)$ is significant. This is despite the fact that these patients were carefully selected for their reliability and were pre-discharge or had a stable mental state. It would be interesting to hear if fellow organisers or examiners have had similar (or worse) experiences!

\section{St Charles Hospital \\ Exmoor Street, London W10 6DZ}

SEAN LYNCH

\section{Whither the MRCPsych day release courses?}

\section{DeAR SiRs}

Wessex has a day release course based at Southampton which I suppose is not atypical of the other courses throughout the country. It was set up in 1966, well before the College was founded, to help trainees pass the DPM. In those days there was little postgraduate education in psychiatry outside the main teaching centres. The Wessex school was set up especially to supply courses of formal lectures and to act as a centre for advice and a place where trainees from all over the region could meet with their peer group and supply mutual support during their psychiatric apprenticeship.

Things have changed since then and although course organisers have tried over the years to keep abreast of these changes, there have been stages when the whole system has needed reappraisal. One such time was following the founding of the College and the introduction at the MRCPsych examination and phasing out of the DPM. I feel we are now at another crucial point when the whole system needs reappraisal.

Those who organise MRCPsych courses have no forum in the College in which to discuss their courses. I am writing this letter to pin-point some of the pressures for change which are currently affecting us and to invite the College to set up a national forum where organisers can share ideas and perhaps help each other to work out a national response to the present needs of the trainee. 
Since the introduction of the College 'accreditation' (now 'approval') exercise, each district service provides a considerable amount of postgraduate training. Case conferences and journal clubs are now standard. Study leave is encouraged and the number of academic meetings organised by the Divisions and the various parts of the College have proliferated. Clinical skills are now more often taught in the trainee's base hospital in what is now a more open and questioning climate. Given all this, do trainees still require a day release course?

It is still probably true that basic sciences are more available at the Regional Centre. Neuroanatomy, pathology, neurophysiology, neuropharmocology, ethology, to name but a few subjects which are relevant, are usually not available outside the teaching centre. The basic sciences used to be concentrated in the first year course. Now the new examination requires more to do with the clinical interview and basic phenomenology, and basic sciences are required in the Part II. Should we still concentrate the basic sciences in the first year on the assumption that they still form the basis of psychiatry or spread them throughout the course?

The Southampton course used to assume that basic clinical skills were taught at the base hospital. However, the new Part I has brought an increased demand for these to be taught on the first year course. How can skills training be incorporated without more didactic parts of the course being dropped?

Over the last two years we have radically altered the MRCPsych course and are now incorporating a research element as a course within the Part II course. We get feedback from our trainees and we can find out examination results (sometimes with difficulty). Is this information good enough or should our courses be judged by some other criterion? Certainly approval teams seem only to check whether a course exists or not prior to giving their approval or not. The approval teams do not have the time or the remit to look critically at individual courses.

My feeling is that the College should now take a closer interest in MRCPsych courses. Their funding will inevitably be questioned in the near future. Are they still needed as is implied on Approval team visits when approval may depend on their existence? Perhaps the Dean should encourage more interest in this rather neglected aspect of training. Some central collection of information on existing courses might form the basis for a meeting of course organisers to share ideas about the future of these courses.

University Department of Psychiatry

Peter NotT

Royal South Hants Hospital

Southampton SO9 4PE
DEAR SIRS

Dr Nott's letter is timely and well taken. The College should be looking at MRCPsych courses once again although it is certainly not the intention to jeopardise their jealously preserved independence. The Chief Examiner recently carried out a survey of MRCPsych courses and the results of this will be made known at the next meeting of the Education Committee.

There is still a need for day-release courses in psychiatry as the undergraduate medical curriculum still gives very much less background for postgraduate trainees in psychiatry than, for example, in general medicine. Medical undergraduate teaching in psychology and sociology is still very much less intensive than anatomy, physiology or pathology; the clerkship in psychiatry is much shorter than either that for medicine or surgery. This means that trainees coming into psychiatry have less theoretical background in their specialty than their colleagues and contemporaries in other medical specialties; it is important that they obtain this background, both for building their subsequent psychiatric knowledge and for communicating with other professionals in the mental health services.

Ideally, teaching of the basic sciences should now be spread throughout the MRCPsych course. It may be difficult to achieve this but it is more in line with the current aim of making basic sciences more relevant to clinical experience.

It is still the intention that basic clinical skills should be taught at the base hospital. Approval visits to training schemes enquire about the training in clinical skills. More theoretical aspects of training in psychiatry are of greater relevance to MRCPsych courses.

I would agree that there is a need for a meeting of course organisers. One of the matters for discussion would be the criteria for success of an MRCPsych course. I am grateful to Dr Nott for raising this important issue.

Professor ANDRew Sims Dean

\section{Auditing of audit}

\section{DEAR SIRS}

The Royal College of Psychiatrists Working Party on Medical Audit (1989) recommends that "every consultant should be allowed to devote one session a week to audit". This is substantially more than the one session a month which has been recommended elsewhere (Health Service Journal, 1988).

If we assume that a consultant is paid between $£ 30,000-£ 40,000$ then one session a week would represent a cost of $£ 3,000-£ 4,000$ per year depending on the consultant's contract. It would represent a loss of 